\title{
Compromised Glutamate Transport in Human Glioma Cells: Reduction-Mislocalization of Sodium-Dependent Glutamate Transporters and Enhanced Activity of Cystine-Glutamate Exchange
}

\author{
Zu-Cheng Ye, ${ }^{1}$ Jeffrey D. Rothstein, ${ }^{2}$ and Harald Sontheimer ${ }^{1}$ \\ ${ }^{1}$ Department of Neurobiology, The University of Alabama at Birmingham, Birmingham, Alabama 35294, and \\ 2Department of Neurology, Johns Hopkins University, Baltimore, Maryland 21287
}

Elevated levels of extracellular glutamate ([Glu $\left.]_{0}\right)$ can induce seizures and cause excitotoxic neuronal cell death. This is normally prevented by astrocytic glutamate uptake. Neoplastic transformation of human astrocytes causes malignant gliomas, which are often associated with seizures and neuronal necrosis. Here, we show that $\mathrm{Na}^{+}$-dependent glutamate uptake in glioma cell lines derived from human tumors (STTG-1, D-54MG, D-65MG, U-373MG, U-251MG, U-138MG, and CH-235MG) is up to 100 -fold lower than in astrocytes. Immunohistochemistry and subcellular fractionation show very low expression levels of the astrocytic glutamate transporter GLT-1 but normal expression levels of another glial glutamate transporter, GLAST. However, in glioma cells, essentially all GLAST protein was found in cell nuclei rather than the plasma membrane. Similarly, brain tissues from glioblastoma patients also display reduction of GLT-1 and mislocalization of GLAST. In glioma cell lines, over
$50 \%$ of glutamate transport was $\mathrm{Na}^{+}$-independent and mediated by a cystine-glutamate exchanger (system $\mathrm{x}_{\mathrm{c}}{ }^{-}$). Extracellular L-cystine dose-dependently induced glutamate release from glioma cells. Glutamate release was enhanced by extracellular glutamine and inhibited by $(S)$-4-carboxyphenylglycine, which blocked cystine-glutamate exchange. These data suggest that the unusual release of glutamate from glioma cells is caused by reduction-mislocalization of $\mathrm{Na}^{+}$-dependent glutamate transporters in conjunction with upregulation of cystineglutamate exchange. The resulting glutamate release from glioma cells may contribute to tumor-associated necrosis and possibly to seizures in peritumoral brain tissue.

Key words: brain tumor; glutamate transporter; glutamate release; cystine-glutamate exchange; system $x_{c}{ }^{-}$; excitotoxicity; epilepsy
Glutamate is the primary excitatory amino acid neurotransmitter in the mammalian CNS. Maintenance of low extracellular glutamate concentrations $\left([\mathrm{Glu}]_{\mathrm{o}}\right)$ is critical to ensure synaptic transmission and to prevent neurotoxicity (Choi, 1988; Nicholls and Attwell, 1990). Toxicity from elevated [Glu $]_{\text {o }}$ (excitotoxicity) has been suggested to be involved in a wide spectrum of acute and chronic nervous system diseases (Olney, 1982; Choi, 1988; Lipton and Rosenberg, 1994). In the healthy brain, abnormal rises of $[\mathrm{Glu}]_{\mathrm{o}}$ to excitotoxic levels are prevented by the activities of $\mathrm{Na}^{+}$-dependent glutamate transporters. To date, five transporter subtypes have been cloned (Kanai and Hediger, 1992; Pines et al., 1992; Storck et al., 1992; Fairman et al., 1995; Arriza et al., 1997). These include the glutamate transporters GLAST and GLT-1, which are primarily expressed by astrocytes (Rothstein et al., 1994; Torp et al., 1994; Lehre et al., 1995) and appear to be the most abundant glutamate transporters in brain (Lehre and Danbolt, 1998). Because astrocytes are in close proximity to synapses, they are believed to play a pivotal role in maintaining glutamate

Received May 26, 1999; revised Sept. 7, 1999; accepted Oct. 6, 1999.

This research was supported by National Institutes of Health Grants R01-NS31234 and R01-NS-36692 and American Cancer Society Grant RPG-97-083. We thank the Brain Tumor Tissue Bank (London, Ontario, Canada), the National Cancer Institute of Canada, and the Brain Tumor Foundation of Canada for providing tumor samples. We are grateful to Dr. Susan Lyons and Jeffrey O'Neal for preparing tissue sections.

Correspondence should be addressed to Dr. Harald Sontheimer, Department of Neurobiology, The University of Alabama at Birmingham, 1719 6th Avenue South, CIRC 545, Birmingham, AL 35294. E-mail: hws@nrc.uab.edu.

Copyright (C) 1999 Society for Neuroscience 0270-6474/99/1910767-11\$05.00/0 homeostasis (Bergles and Jahr, 1998; Magistretti et al., 1999). Astrocytes can convert transported glutamate to glutamine, which is then released as precursor for neuronal synthesis of neurotransmitter glutamate (Rothstein and Tabakoff, 1984; Waniewski and Martin, 1986; Laake et al., 1995; Sibson et al., 1997).

Under disease conditions, glial glutamate transport can be impaired and may contribute to the elevation of $[\mathrm{Glu}]_{\mathrm{o}}$. For instance, GLT-1 expression is severely decreased in the motor cortex and spinal cord of patients with the sporadic form of amyotrophic lateral sclerosis, leading to elevations of excitatory amino acids in the CSF (Rothstein et al., 1990, 1995). Direct links between compromised glutamate transport and neurotoxicity have been demonstrated through knock-out experiments. Suppression of the astrocytic glutamate transporters GLT-1 and GLAST by antisense oligonucleotides caused drastic rises in $[\mathrm{Glu}]_{\mathrm{o}}$, sufficient to induce neuronal damage (Rothstein et al., 1996). GLT-1 knock-out mice undergo lethal spontaneous epileptic seizures and display increased susceptibility to acute brain injury (Tanaka et al., 1997), whereas mice in which the neuronal glutamate transporter EAAC-1 had been knocked out developed neither neurodegeneration nor epilepsy (Peghini et al., 1997).

Elevation of $[\mathrm{Glu}]_{\mathrm{o}}$ may not only arise from reduced expression of glutamate transporter but can also be caused by the reversed operation of glutamate transport or by other pathways that can mediate glutamate efflux. All the cloned $\mathrm{Na}^{+}$-dependent transporters are driven by the electrochemical gradients for $\mathrm{Na}^{+}, \mathrm{K}^{+}$, 
and $\mathrm{H}^{+}$to transport glutamate against its steep transmembrane gradient (Attwell et al., 1993; Zerangue and Kavanaugh, 1996a). Compromising the ionic environment can lead to reversal of transport. Then the millimolar cytoplasmic concentrations of glutamate in astrocytes (Hertz et al., 1988; Levi and Patrizio, 1992) can become a significant source for nonvesicular glutamate release, which may contribute to neuronal injury (Szatkowski et al., 1990; Longuemare and Swanson, 1995). In addition to reversal of transport, swelling-activated anion channels have also been shown to mediate efflux of amino acids, including glutamate (Kimelberg and Mongin, 1998). Furthermore, an $\mathrm{Na}^{+}$independent cystine-glutamate exchange (equal to system $\mathrm{x}_{\mathrm{c}}{ }^{-}$in fibroblast) (Bannai and Kitamura, 1980), which has recently been cloned (Sato et al., 1999), is expressed by a variety of cell types (Watanabe and Bannai, 1987; Cho and Bannai, 1990; Murphy et al., 1990; Piani and Fontana, 1994). Intracellular glutamate concentrations in astrocytes are at levels above $1 \mathrm{~mm}$ (Hertz et al., 1988), whereas L-cystine levels are presumably much lower because intracellular L-cystine is readily reduced to L-cysteine (Bannai and Kitamura, 1980). Consequently, the transmembrane glutamate gradient likely favors the efflux of glutamate in exchange for cystine. L-Cystine is required for the synthesis of glutathione (Sato et al., 1998).

Unlike most neurons, glial cells can proliferate in response to injury or under neoplastic conditions. The vast majorities of primary brain neoplasms derived from glial cells and are collectively called gliomas. These tumors are rapidly expanding and are often associated with seizures (Paillas, 1994). We show here that glioma cells show much reduced cell surface expression of $\mathrm{Na}^{+}$dependent glutamate transporters thereby compromising their ability to maintain glutamate homeostasis. The resulting glutamate accumulation in the extracellular space may contribute to seizures that are common in glioma patients. In addition, glioma cells may actively kill neurons in the vicinity of the tumor through the release of glutamate by cystine-glutamate exchange.

\section{MATERIALS AND METHODS}

Materials. The enzymes NADPH:FMN oxidoreductase, glutamate dehydrogenase, and propidium iodide were purchased from Boehringer Mannheim (Indianapolis, IN). General cell culture supplies were obtained from Becton Dickinson (Franklin Lakes, NJ) and Corning (Corning, NY). Earle's minimum essential media (MEM) and DMEM were obtained from Life Technologies (Grand Island, NY). Fetal bovine serum (FBS) was purchased from Hyclone (Logan, UT). S-4carboxyphenylglycine ( $S$-4CPG), $(S)$-3-carboxy-4-hydroxyphenylglycine $(S$-3C4H-PG), $(S)$-4-carboxy-3-hydroxyphenylglycine ( $S$-4C3H-PG), and $(R)$-4-carboxyphenylglycine $(R-4 \mathrm{CPG})$ were purchased from Tocris Cookson (Bristol, UK). All radioactive tracers and enhanced chemiluminescence (ECL) kits were purchased from Amersham (Arlington Heights, IL). Unless stated otherwise, other enzymes and chemicals were purchased from Sigma (St. Louis, MO).

Cell lines and primary cultures of rat astrocytes. Glioma cell lines used in these studies included STTG-1 (CCF-STTG1, CRF 1718) (from American Type Culture Collection, Manassas, VA), U-138MG, U-251MG, U-373MG, CH-235MG, D-54MG, and D-65MG (all from Dr. D. D. Bigner, Duke University, Durham, NC). These cell lines were cultured in DMEM supplemented with $10 \%$ heat-inactivated FBS. Glioma cells were used 2-5 d after plating at which time they had reached $\sim$ $80 \%$ confluence. Unless mentioned otherwise, experiments were performed on STTG-1 cells and repeated on at least three other cell lines.

Hippocampal astrocytes were prepared from Sprague Dawley rats as described previously (Ye and Sontheimer, 1998). Briefly, hippocampi were removed from the decapitated rat pups [postnatal day (P) P0-P2], freed of meninges, minced into $1 \mathrm{~mm}^{3}$ pieces, and digested in papain solution for $20-30 \mathrm{~min}$. Cells were plated in 24 well plates or flasks in MEM supplemented with $10 \%$ FBS, $20 \mathrm{~mm}$ glucose, $10 \mathrm{U} / \mathrm{ml}$ penicillin, and $10 \mu \mathrm{g} / \mathrm{ml}$ streptomycin. Culture media for astrocytic cultures was changed twice a week, and astrocytes were used after $10 \mathrm{~d}$ in culture, at which time $>90 \%$ of cells were GFAP-positive and essentially free of neurons.

Glutamate-aspartate uptake. Uptake procedures were similar to those we have described previously (Ye and Sontheimer, 1996) with minor modifications. ${ }^{3} \mathrm{H}$-D-aspartate and D-aspartate as stable glutamate ana$\operatorname{logs}$ were used to study high-affinity, $\mathrm{Na}^{+}$-dependent glutamate uptake. In some cultures, results were compared with ${ }^{3} \mathrm{H}$-glutamate uptake. The solution for uptake consisted of (in mM): $125 \mathrm{NaCl}, 3.0 \mathrm{KCl}, 2.0 \mathrm{CaCl}_{2}$, $1.25 \mathrm{NaH}_{2} \mathrm{PO}_{4}, 23 \mathrm{NaHCO}_{3}, 10$ glucose, and $2.0 \mathrm{MgSO}_{4}$, warmed to $37^{\circ} \mathrm{C}$ and saturated with $5 \% \mathrm{CO}_{2}-95 \% \mathrm{O}_{2}$. For experiments dealing with $\mathrm{Na}^{+}$-independent glutamate-aspartate uptake, $\mathrm{NaCl}$ was replaced by choline chloride or $N$-methyl-D-glucamine, $\mathrm{NaH}_{2} \mathrm{PO}_{4}$ was replaced by $\mathrm{KH}_{2} \mathrm{PO}_{4}$ with $\mathrm{KCl}$ lowered by $1.25 \mathrm{~mm}$, and $\mathrm{NaHCO}_{3}$ was replaced with triethylammonium bicarbonate (Kimelberg et al., 1989). Cells were washed twice with the above uptake solution before experiments commenced. The above uptake solution supplemented with $0.1 \mathrm{~mm}$ D-aspartate and $0.5 \mu \mathrm{Ci} / \mathrm{ml}^{3} \mathrm{H}$-D-aspartate was then added for $10 \mathrm{~min}$. Uptake was terminated by three washes with ice-cold PBS. Cells were then dissolved in $0.3 \mathrm{~N} \mathrm{NaOH}$ and aliquoted. ${ }^{3} \mathrm{H}$ activity was detected in a liquid scintillation counter (Beckman Instruments, Fullerton, CA) and normalized to protein contents as determined by the Bio-Rad protein assay kit (Bio-Rad, Hercules, CA). Background radioactivity was determined in the same manner as uptake but with the presence of $10 \mathrm{~mm}$ unlabeled glutamate or D-aspartate and was subtracted from the uptake reading.

To determine the kinetics of uptake, ${ }^{3} \mathrm{H}$-glutamate and ${ }^{3} \mathrm{H}$-D-aspartate uptake was performed in the presence of 5.0-400 $\mu \mathrm{M}$ glutamate or D-aspartate, respectively. Apparent $V_{\max }$ and $K_{\mathrm{m}}$ were determined from the double reciprocal plot of uptake rate versus substrate concentration (Lineweaver-Burk plot) or from Eadie-Hofstee plots.

L-cystine uptake. ${ }^{35} \mathrm{~S}$-L-cystine uptake was performed in a way similar to glutamate uptake. Because intracellular cystine can be quickly reduced to cysteine and released back into the media (Bannai and Ishii, 1982), the time course of uptake was shortened to a $3 \mathrm{~min}$ period to minimize loss of intracellular ${ }^{35} \mathrm{~S}$. For kinetic measurements, L-cystine concentrations in the uptake media ranged from 15 to $400 \mu \mathrm{M}$.

Sampling and determination of extracellular and intracellular glutamate levels. Cells were washed twice and incubated in glutamate-depleted culture media (Ye and Sontheimer, 1998) or Earle's balanced salt solution (EBSS) (supplemented with $10 \mathrm{~mm}$ D-glucose) with various testing agents and the supernatant collected for $[\mathrm{Glu}]_{\mathrm{o}}$ measurement. After experiments, cells were washed twice with PBS, harvested in $0.3 \mathrm{~N}$ $\mathrm{NaOH}$, and then neutralized with $0.3 \mathrm{~N} \mathrm{HCl}$. Aliquots were stored at $-20^{\circ} \mathrm{C}$ for later protein and $[\mathrm{Glu}]_{\mathrm{i}}$ determination. Samples containing serum and samples with glutamate levels higher than $20 \mu \mathrm{M}$ were diluted 1:20-1:100 with distilled water before measurement.

Glutamate concentration was determined by the bioluminescence method as described by Fosse et al. (1986) with minor modifications. Briefly, the glutamate-specific reagent mixture contained: potassium phosphate $25 \mathrm{~mm}, \mathrm{pH} 7.0$, Triton X-100 $40 \mu \mathrm{g} / \mathrm{ml}$, dithiothreitol $100 \mu \mathrm{M}$, myristyl aldehyde $30 \mu \mathrm{M}, \beta$-NAD $2 \mathrm{~mm}$, ADP $250 \mu \mathrm{M}$, FMN $2.5 \mu \mathrm{M}$, luciferase $60 \mu \mathrm{g} / \mathrm{ml}$, NADPH:FMN oxidoreductase $300 \mathrm{mU} / \mathrm{ml}$, and glutamate dehydrogenase $0.5 \mathrm{mg} / \mathrm{ml}$. Samples with a volume of $10 \mu \mathrm{l}$ were placed in white 96 well plates (Labsystem, Franklin, MA). Luminescence generated by the reaction of glutamate with the above reagent mixture $(80 \mu \mathrm{l} /$ well $)$ was measured by a luminescence plate reader (LUM Istar; BMG LabTechnologies, Durham, NC). Luminescence readings remained linear within a glutamate range of $20 \mathrm{nM}$ to $10 \mu \mathrm{M}$. We determined that all drugs used in these studies did not interfere with the bioluminescence assay at the concentrations used. Glutamate standards used for calibration were prepared in corresponding glutamate-free solutions. $[\mathrm{Glu}]_{\mathrm{i}}$ was calculated, normalized to protein contents, and expressed as nanomoles per milligram protein. [Glu] was either expressed as absolute concentration or multiplied by the volume then normalized to cellular protein levels and expressed as nanomoles per milligram protein.

Immunofluorescence microscopy. Glioma cells and control rat hippocampal astrocytes used for immunocytochemistry were cultured on glass coverslips. Cells were washed twice in PBS and fixed in $4 \%$ paraformaldehyde for $10 \mathrm{~min}$. This was followed with three rinses in TBS (Tris- $\mathrm{HCl}$ buffer solution, $\mathrm{pH}$ 7.4) and incubated $30 \mathrm{~min}$ in blocking solution (TBS plus $5 \%$ normal goat serum plus $0.1 \%$ Triton X-100). Cells were then incubated overnight with anti-GLAST antibody (diluted in blocking solution to $0.4 \mu \mathrm{g} / \mathrm{ml}$ ) at $4^{\circ} \mathrm{C}$. After removing the primary antibody, the cells were rinsed three times ( 5 min each) with blocking 
solution and incubated with FITC-conjugated goat anti-rabbit IgG for 2 $\mathrm{hr}$ at room temperature. Finally, cells were washed four times and mounted on glass slides with fluorescent microscopy mounting solution and sealed with nail polish. Cell staining was examined with a Leica (Nussloch, Germany) DMRB microscope with a $100 \times$ oil objective, and images were captured by a camera and frame-grabber system (Optronics Engineering, Goleta, CA).

Surgically removed human glioma tissue and corresponding uninvolved brain tissue from the same patients were freshly embedded in OCT, sectioned to $8-10 \mu \mathrm{m}$ on a cryotome (Zeiss HM505E; Zeiss, Oberkochen, Germany), and mounted on Fisherbrand Plus microscopic slides. These experiments were approved by the Institutional Review Board of the University of Alabama at Birmingham (IRB F971030027). Subsequently, these samples were subject to the same immunohistochemical procedures as described for culture cells above. Propidium iodide (10 $\mu \mathrm{g} / \mathrm{ml}$ ) was applied together with FITC-conjugated goat anti-rabbit antibodies as a nuclear (DNA) counterstain. Double stainings were superimposed in Adobe PhotoShop (Adobe Systems, Mountain View, CA).

Cellular fractionation. Cellular fractionation was conducted in two ways, with all steps performed at $4^{\circ} \mathrm{C}$. Cultured glioma cells were washed twice with cold PBS, scraped from the culture plates with a rubber policeman, and pelleted with a 5 min spin at $2000 \times g$. The collected cell pellet was homogenized with Potter-Elvehjem tissue grinders in Tris$\mathrm{HCl}(25 \mathrm{mM}, \mathrm{pH} 7.40)$ buffered homogenization solution containing 0.3 $\mathrm{M}$ sucrose and $2 \mathrm{~mm}$ EDTA, supplemented with protease inhibitors $(0.5$ mM PMSF, $10 \mu \mathrm{g} / \mathrm{ml}$ leupeptin, $1 \mu \mathrm{g} / \mathrm{ml}$ pepstatin A, and $1 \mu \mathrm{g} / \mathrm{ml}$ aprotinin). Cellular fractions were separated by differential centrifugation. The homogenate was first centrifuged at $1000 \times g$ for $5 \mathrm{~min}$. The pellet was then resuspended in homogenization solution and centrifuged against a $36 \%$ sucrose cushion at $10,000 \times g$ for $10 \mathrm{~min}$. The resulting nuclear pellet was then collected as nuclei part. The supernatant from the initial $1000 \times g$ spin was subsequently centrifuged at $20,000 \times g$ for 20 min to isolate the plasma membrane and other high-density membrane structures. The supernatant from this step was further centrifuged at $200,000 \times g$ with a Beckman Instruments T70.1 rotor for $60 \mathrm{~min}$ to yield a pellet (P200) containing low-density membrane, vesicles, and a supernatant (S-200) containing mainly soluble proteins.

For comparison, a modified method using digitonin (Stachowiak et al., 1994; Bronfman et al., 1998) was used to isolate cell nuclei. The collected cell pellet was resuspended in nuclei buffer containing $0.1 \%$ digitonin and (in $\mathrm{mm}$ ): 5 sodium phosphate, $\mathrm{pH} 7.4,50 \mathrm{NaCl}, 5 \mathrm{KCl}, 150$ sucrose, 2 dithiothreitol, $1 \mathrm{MgCl}_{2}$, and $0.5 \mathrm{CaCl}_{2}$, supplemented with protease inhibitors. Suspended cells were then homogenized in a Dounce tissue grinder with 10 gentle strokes. The resulting homogenate was centrifuged at $500 \times g$ for $10 \mathrm{~min}$ at $4^{\circ} \mathrm{C}$, and the pellet was resuspended in nuclei buffer and centrifuged through a $30 \%$ sucrose solution at $1000 \times$ $g$ for $10 \mathrm{~min}$. These procedures yielded a purified nuclear pellet $(\mathrm{N})$, and the remaining nuclear supernatant (NS) on the top of the sucrose cushion mainly contained cell nuclei that were associated with some other membrane structure. The supernatant from $500 \times g$ was further centrifuged at $60,000 \times g$ for $30 \mathrm{~min}$, and the pellet (P-60) and supernatant (S-60) contain cell debris and soluble cytoplasmic proteins, respectively.

Biotinylation. To separate transporters in the plasma membrane from intracellular transporters, a method for biotinylation was modified from Qian et al. (1997) and Davis et al. (1998). Briefly, cells cultured in $10 \mathrm{~cm}$ dishes were quickly washed with $\mathrm{PBS}-\mathrm{Ca} / \mathrm{Mg}$ solution (in $\mathrm{mM}$ ): 138 $\mathrm{NaCl}, 2.7 \mathrm{KCl}, 1.5 \mathrm{KH}_{2} \mathrm{PO}_{4}, 8.0 \mathrm{Na}_{2} \mathrm{HPO}_{4}, 1 \mathrm{MgCl}_{2}$, and $0.1 \mathrm{CaCl}_{2}, \mathrm{pH}$ 7.4. This was followed by incubation with $3.0 \mathrm{ml}$ of Sulfo-NHS-biotin (Pierce, Rockford, IL) solution $(1.5 \mathrm{mg} / \mathrm{ml}$ in PBS- $\mathrm{Ca} / \mathrm{Mg}$ solution) for $30 \mathrm{~min}$ at $4^{\circ} \mathrm{C}$ with occasional gentle shaking. Biotinylation was quenched by double washing and an additional $30 \mathrm{~min}$ incubation with $100 \mathrm{~mm}$ glycine in PBS $-\mathrm{Ca} / \mathrm{Mg}$. The cells were then rinsed with $\mathrm{PBS}-\mathrm{Ca} / \mathrm{Mg}$, collected, and then lysed with $0.5-1.5 \mathrm{ml}$ radioimmunoprecipitation assay (RIPA) buffer consisting of $50 \mathrm{~mm}$ Tris-HCl, pH 7.4, $150 \mathrm{~mm} \mathrm{NaCl}, 1 \%$ Triton X-100, $1 \%$ sodium deoxycholate, $1 \mathrm{~mm}$ EDTA, and $0.1 \%$ SDS, supplemented with protease inhibitors. Supernatant from the lysate after centrifugation $\left(20,000 \times g\right.$ for $10 \mathrm{~min}$ at $\left.4^{\circ} \mathrm{C}\right)$ was aliquoted as sample of total lysate, and the rest was incubated with avidin agarose beads $(400 \mu \mathrm{l}$ of beads $/ 1 \mathrm{ml}$ of supernatant; Pierce) for $2 \mathrm{hr}$ at $4^{\circ} \mathrm{C}$. The beads were then centrifuged at $10,000 \times g$ for $5 \mathrm{~min}$, and the supernatant was collected. The beads were washed four times with RIPA, and the absorbed protein was eluted by boiling for 5 min with $200 \mu \mathrm{l}$ of Laemmli's buffer $(62.5 \mathrm{~mm}$ Tris- $\mathrm{HCl}$ at $\mathrm{pH} 6.8,10 \%$ glycerol, $2 \%$ SDS, $5 \% \beta$-mercaptoethanol, and $0.1 \%$ bromophenol blue). Bead elutes $(30 \mu \mathrm{l})$ (contained biotinylated cell surface transporters), total lysate, and the supernatants after beads absorption (contained intracellular transporters, used same volume as total lysate) were separated with SDS-PAGE, and the protein was detected with immunoblotting.

Comparison biotinylation was performed on cells lysed with hypotonic solution (5 min swelling in protease inhibitors supplemented PBS solution diluted with distilled water in 5:95 v/v ratio). The cell debris (mainly membrane and nuclei) was collected by centrifugation at $20,000 \times g$ for $5 \mathrm{~min}$ and then incubated with biotin agents for $30 \mathrm{~min}$. Biotinylation was stopped by glycine (100 mM in PBS), and all the washes were done by centrifugation and resuspension. The final pellet was dissolved in RIPA and then treated the same way as intact cells.

Western blot. The expression of GLT-1 and GLAST by glioma cells was assessed by Western blot. Protein content in cell lysates was determined before adding Laemmli's buffer to samples and boiling for $5 \mathrm{~min}$. Samples were loaded at a volume containing $30 \mu \mathrm{g}$ of protein and separated by $7 \%$ SDS-PAGE. Proteins in the gel were then transferred to polyvinylidene fluoride membrane (Immobilon-P; Millipore, Bedford, MA). The membrane was incubated for $1 \mathrm{hr}$ at room temperature in blocking solution: TBS with $0.1 \%$ Tween 20 (TBS-T), 5\% nonfat dry milk, and $1 \%$ bovine serum albumin and washed twice with TBS-T. The membrane was then probed at room temperature for $1 \mathrm{hr}$ with an affinity-purified antiGLAST antibody $(0.4 \mu \mathrm{g} / \mathrm{ml})$, anti-GLT-1 antibody $(0.04 \mu \mathrm{g} / \mathrm{ml})$, and anti-actin antibody (1:2000) diluted in probing TBS-T (TBS-T supplemented with $0.5 \%$ nonfat dry milk and $1 \%$ BSA). Both transporter antibodies were raised against a homology sequence in rat and human. After washing six times for 5 min each with TBS-T, the blot was incubated for $1 \mathrm{hr}$ with horseradish peroxidase-conjugated goat anti-rabbit IgG (Amersham) diluted 1:1000 in probing TBS-T. After washing, the blots were visualized with ECL and exposed on hypersensitive ECL film.

As a control for cell surface biotinylation, we used $\mathrm{Na}^{+} / \mathrm{K}^{+}$-ATPase as plasma membrane marker. For this purpose, blots probed for transporters were first stripped at $50^{\circ} \mathrm{C}$ for 30 min with $62.5 \mathrm{~mm}$ Tris- $\mathrm{HCl}, \mathrm{pH}$ $6.8,2 \% \mathrm{SDS}$, and $100 \mathrm{~mm} \beta$-mercaptoethanol. This was followed by two washes with TBS-T for 10 min each and blocking in 5\% dry milk and $1 \%$ BSA for $1 \mathrm{hr}$; then the blot was probed with monoclonal anti-Na ${ }^{+} / \mathrm{K}^{+}$ATPase $(0.4 \mu \mathrm{g} / \mathrm{ml}$; Upstate Biotechnology, Lake Placid, NY). Blots were then washed and incubated with peroxidase-labeled anti-mouse secondary antibody (1:1000; Amersham) and visualized with ECL.

\section{RESULTS}

\section{$\mathrm{Na}^{+}$-dependent and $\mathrm{Na}^{+}$-independent glutamate transport in glioma cells}

Using either ${ }^{3} \mathrm{H}$-glutamate or ${ }^{3} \mathrm{H}$-D-aspartate, we studied glutamate and aspartate uptake into human glioma cells and compared the rates of uptake with that of neonatal rat astrocytes. The established human glioma cell lines used for these studies included STTG-1, D-54MG, D-65MG, U-373MG, U-138MG, $\mathrm{U}-251 \mathrm{MG}$, and $\mathrm{CH}-235 \mathrm{MG}$. A representative experiment is illustrated in Figure 1, which shows a direct comparison of glutamate and aspartate uptake in astrocytes (Fig. $1 A$ ) and in STTG-1 cells (Fig. $1 B$ ), a cell line established from a WHO-IV grade human astrocytoma. Data from quadruplicated experiments on each of the seven glioma cells lines are summarized in Table 1. These data show that the uptake of glutamate and aspartate is profoundly reduced in glioma cells compared with normal rat astrocytes. This does not reflect a species difference because rat and human astrocytes have been reported to display similar glutamate uptake (Whittemore et al., 1994). Compared with normal astrocytes, glioma glutamate uptake exhibited an 11-fold to 45-fold reduction in $V_{\max }$ with little alteration in $K_{\mathrm{m}}$. Interestingly, The $\mathrm{Na}^{+}$-dependent uptake of $\mathrm{D}$-aspartate in these glioma cells was further reduced (Fig. 1B, Table 1). With the exception of U-251MG and D-65MG, all glioma cell lines showed 3-fold to 30 -fold lower rates of aspartate uptake than glutamate uptake. This difference was not observed in astrocytes in which $K_{\mathrm{m}}$ values for uptake for D-aspartate and L-glutamate were almost identical, and $V_{\max }$ values differed by $<30 \%$ (Table 1 ). We then determined the contribution of $\mathrm{Na}^{+}$-dependent glutamate uptake by repeating these studies in the presence or absence of extracellular $\mathrm{Na}^{+}$ 


\section{A. Astrocytes}

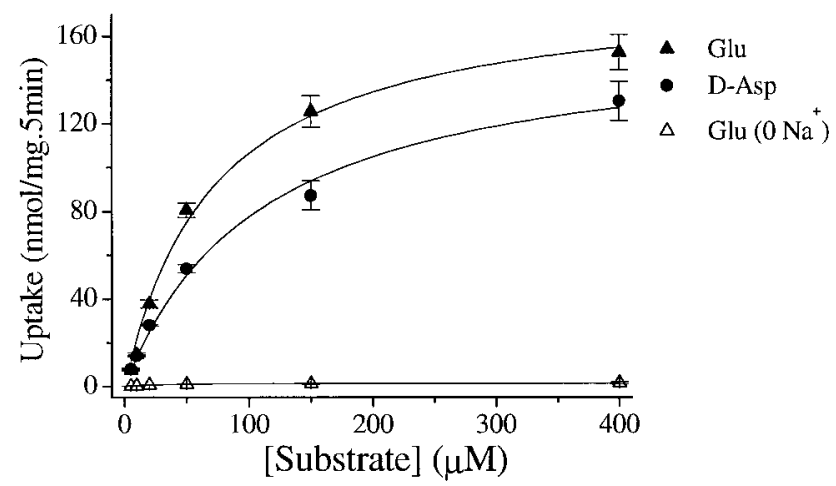

B. STTG-1 glioma cells

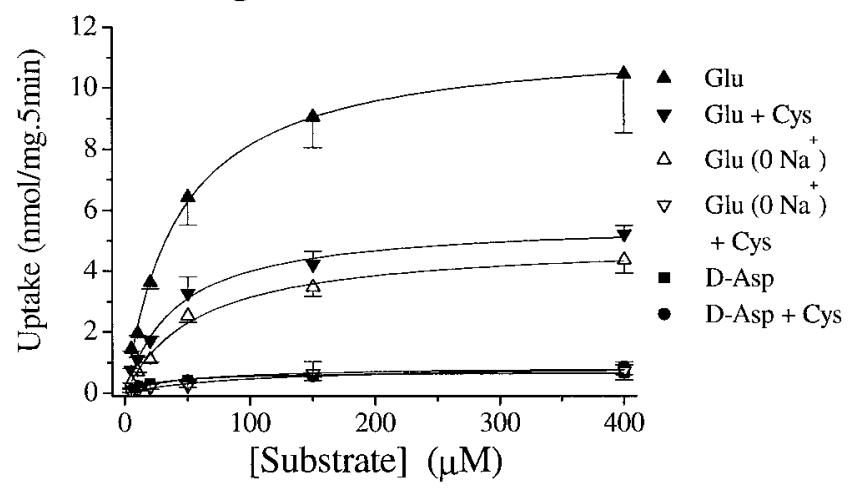

Figure 1. $\mathrm{Na}^{+}$-dependent and $\mathrm{Na}^{+}$-independent glutamate transport in astrocytes and glioma cells. $A$, Astrocytes transport glutamate and $\mathrm{D}$-aspartate at similar rates, and this transport is primarily dependent on the presence of $\mathrm{Na}^{+}$. $B$, STTG-1 glioma cells transport glutamate at much lower rates than astrocytes and are only partially depend on $\mathrm{Na}^{+}$. L-Cystine $(100 \mu \mathrm{M})$ reduced glutamate transport by $\sim 50 \%$ in the presence of $\mathrm{Na}^{+}$but almost completely blocked $\mathrm{Na}^{+}$-independent glutamate uptake. STTG-1 cells transport D-aspartate much less efficiently than glutamate, and this transport is insensitive to L-cystine. Data are means $\pm \mathrm{SE}$; $n=4-6$.

(Fig. 1B, Table 1). Interestingly, glioma cells showed only a $\sim 50 \%$ reduction in glutamate uptake in the absence of $\mathrm{Na}^{+}$, suggesting that up to $50 \%$ of total glutamate uptake in glioma cells is $\mathrm{Na}^{+}$-independent. In astrocytes, in contrast, essentially all glutamate uptake was abolished in $\mathrm{Na}^{+}$-free media (Fig. 1A). Importantly, the $\mathrm{Na}^{+}$-independent glutamate uptake in glioma cells was sensitive to L-cystine, whereas the D-aspartate uptake was not (Fig. 1B). Together, these data suggest that $\mathrm{Na}^{+}$dependent glutamate uptake in glioma cells is markedly reduced, but $\mathrm{Na}^{+}$-independent glutamate uptake is upregulated.

\section{Glioma cells lack surface expression of GLAST}

Numerous studies have reported reduced transport rates as a result of reduced levels of transporter protein expression. In astrocytes, GLAST and GLT-1 are the major $\mathrm{Na}^{+}$-dependent glutamate transporters. We thus set out to study and compare expression levels of GLAST and GLT-1 in astrocytes and glioma cells by Western blot (Fig. 2). To ensure that protein levels were comparable under each condition, we also probed for actin in each blot. Western blot of whole-cell lysates consistently showed very little expression of GLT-1 protein in glioma cells, whereas both hippocampal and cortical astrocytes showed prominent ex- pression of GLT-1. However, all glioma cell lines (except U-251MG) showed prominent expression of GLAST (Fig. 2). Interestingly, GLAST expression levels in U-251MG were less than all other cell lines on Western blot, and the band recognized by the antibodies showed a somewhat lower apparent molecular weight ( $\sim 5 \mathrm{kDa}$ smaller).

In light of the high levels of GLAST expression, one would expect that glioma cells are quite capable of transporting glutamate, although experiments in Figure 1 suggest the contrary. To ensure that GLAST is indeed expressed in the plasma membrane, we set out to determine the subcellular distribution of GLAST in astrocytes and glioma cells using immunocytochemistry. In astrocytes, GLAST appeared to be expressed on the cell surface with enhanced labeling along contact sites between cells and little staining in the cytoplasm or intracellular organelles (Fig. $3 A$ ). In contrast, in glioma cells, the cell nuclei were prominently labeled by GLAST antibodies with little immunoreactivity elsewhere, as illustrated for three representative examples from STTG1, D-54MG, and D-65MG cells, respectively (Fig. 3B-D).

To ensure that the nuclear localization of GLAST is not just a feature of glioma cell lines, we also examine the localization of GLT-1 and GLAST in human biopsy sections from glioblastoma multiforme (GBM) surgically resected from five patients. As with the cell lines, we consistently observed most of the GLAST immunoreactivity in the cells nuclei (Fig. $3 E$ ). We double labeled these sections also with propidium iodide (Fig. $3 F$ ), and the superimposition of these images (Fig. $3 G$ ) further emphasizes the nuclear localization of GLAST in the cell nuclei. In contrast, uninvolved tissue from the same patient showed prominent GLAST immunoreactivity localized outside the cells nuclei (Fig. $3 H$ ). In four of the five biopsies examined, we observed GLAST immunoreactivity exclusively in the cell nuclei. In one, we observed both weak nuclear and membrane staining. In contrast, we rarely observed any GLAST immunoreactivity in cell nuclei in comparison tissues. The few cells that did show nuclear staining may indeed be glioma cells that have invaded normal brain. GLT-1 immunoreactivity was either weak or absent in GBM tissue (Fig. 3I) but was prominent in comparison tissue (Fig. $3 J$ ). Interestingly, we occasionally encountered areas in GBM tissue sections in which the labeling pattern changed abruptly, an example of which is shown in Figure $3 K$. Here, GLT-1 staining was absent in the area that has a high nuclear density but prominent in the area with only a few cell nuclei. These areas may be the boundaries between the tumor and normal brain.

Cell surface expression of GLAST was further studied by biotinylation of surface proteins and subsequent separation by binding to avidin-conjugated agarose beads. The resulting biotinylated proteins were run on SDS gels and probed with antibodies to GLAST. For control purposes, the blot was stripped and probed with antibodies that recognize the $\mathrm{Na}^{+} / \mathrm{K}^{+}$-ATPase, which is ubiquitously expressed in cell membranes, and with actin, a ubiquitous cytoplasmic protein. Although the majority of the $\mathrm{Na}^{+} / \mathrm{K}^{+}$-ATPase was localized in the bead elutes, which contained extracted biotinylated cell surface proteins (Fig. 4B), no GLAST was found in the cell surface fractions but remained in the intracellular fractions (Fig. $4 A$ ), and the latter also showed staining at $\sim 160 \mathrm{kDa}$, which is likely a GLAST multimer (Haugeto et al., 1996). To confirm that the lack of biotinylated GLAST was indeed caused by a lack of surface expression resulting in the inaccessibility of the biotinylating reagent, similar experiments were performed on glioma cells that were lysed by osmotic shock. Under those conditions, GLAST could be de- 


\begin{tabular}{|c|c|c|c|c|c|c|}
\hline & $\begin{array}{l}\text { D-Asp } \\
\left(V_{\max }\right)\end{array}$ & $\begin{array}{l}\text { D-Asp } \\
\left(K_{\mathrm{m}}\right)\end{array}$ & $\begin{array}{l}\text { Glutamate } \\
\left(V_{\max }\right)\end{array}$ & $\begin{array}{l}\text { Glutamate } \\
\left(K_{\mathrm{m}}\right)\end{array}$ & $\begin{array}{l}\text { Glutamate } \\
\left(0 \mathrm{Na}^{+} V_{\max }\right)\end{array}$ & $\begin{array}{l}\text { Glutamate } \\
\left(0 \mathrm{Na}^{+} K_{\mathrm{m}}\right) \\
\end{array}$ \\
\hline STTG-1 & 0.28 & 35.8 & 2.52 & 43.5 & 1.33 & 71.8 \\
\hline D-54MG & 0.05 & 23.0 & 1.65 & 127 & 0.66 & 90.8 \\
\hline D-65MG & 2.01 & 16.8 & 2.95 & 35.8 & 0.88 & 38.3 \\
\hline U-373MG & 0.29 & 51.7 & 2.57 & 99.3 & 1.10 & 133 \\
\hline U-138MG & 0.27 & 40.0 & 1.06 & 65.2 & 0.88 & 668 \\
\hline $\mathrm{U}-251 \mathrm{MG}$ & 3.17 & 22.9 & 3.53 & 42.4 & 0.77 & 45.4 \\
\hline $\mathrm{CH}-235 \mathrm{MG}$ & 0.24 & 30.9 & 0.86 & 127 & 0.73 & 143 \\
\hline Astrocyte & 28.8 & 82.2 & 40.1 & 84.4 & 0.63 & 68.6 \\
\hline
\end{tabular}

Unit of $V_{\max }, \mathrm{nmol} \cdot \mathrm{mg}^{-1} \cdot \mathrm{min}^{-1}$; unit of $K_{\mathrm{m}}, \mu \mathrm{M}$. Data were pooled from quadruplicated experiments.

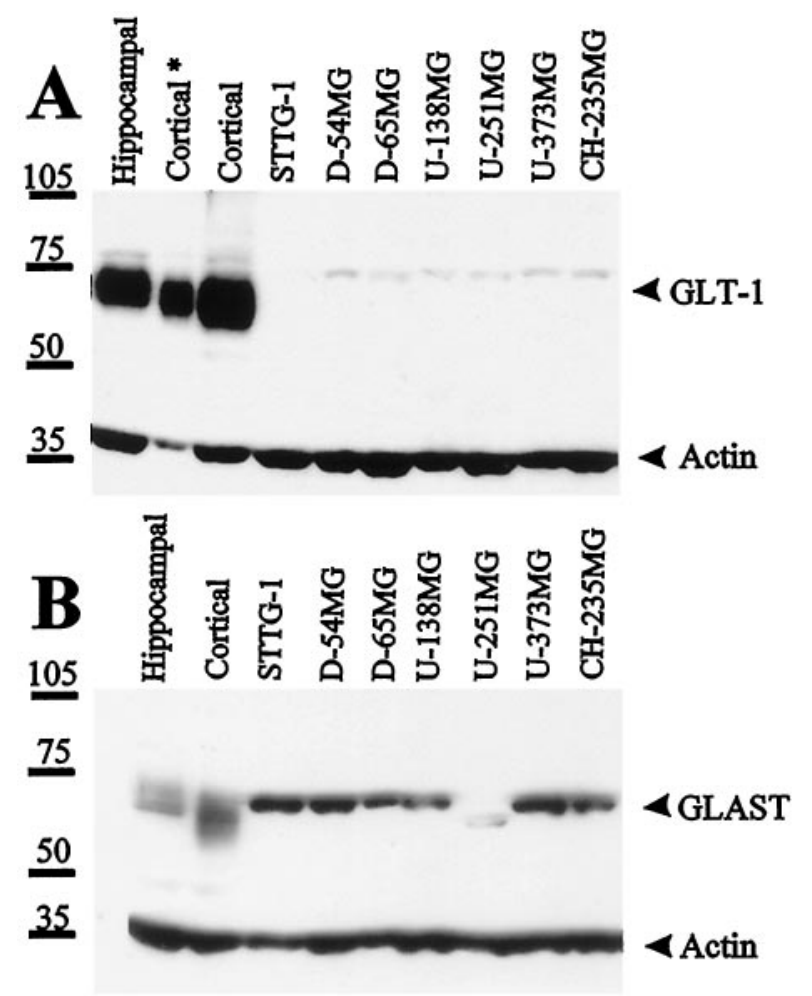

Figure 2. Differential expression of glutamate transporters GLT-1 and GLAST in cultured rat hippocampal and cortical astrocytes and seven human glioma cell lines; $30 \mu \mathrm{g}$ (Cortical* ${ }^{*}, 10 \mu \mathrm{g}$ ) of protein of each whole-cell lysate were used and probed for the expression of GLT-1 and GLAST. Blots were also probed with anti-actin as loading control. Rat astrocytes (12 d in vitro) expressed abundant GLT-1, whereas human glioma cells virtually lacked GLT-1, except for a small amount of protein appearing as faint a band that was $\sim 10 \mathrm{kDa}$ bigger than rat GLT-1. Most glioma cell lines expressed comparable amounts of GLAST as rat astrocytes, except U-251MG expressed less amount of GLAST that appeared $\sim 5 \mathrm{kDa}$ smaller.

tected in the biotinylated fraction (Fig. 4C). These data thus support the lack of cell surface expression of GLAST. GLAST expression in glioma cells is most likely confined to the nuclear membrane, as was seen immunohistochemically (Fig. 3B-D). Because the cell nuclei are the heaviest cell organelles, they were separated first from other cellular components by differential centrifugation. In all tested glioma cells, most immunoreactivity was found in the nuclear fraction. The P-20 fraction, which stained for the plasma membrane marker $\mathrm{Na}^{+} / \mathrm{K}^{+}$-ATPase, showed only small amounts of GLAST, which was most likely a result of GLAST contained in the endoplasmic reticulum found in this fraction. Interestingly, GLAST immunoreactivity was also detected in the P-200 fraction, which mainly consists of Golgi and other low-density vesicles; however, the band appeared at a molecular weight of $\sim 160 \mathrm{kDa}$, possibly a multimer of GLAST (Haugeto et al., 1996). Again, there was no GLAST detected in the soluble fraction (Fig. 4D, S-200). Similarly, cell nuclei isolated by digitonin pretreatment followed with centrifugation at $500 \times g$ also contained high levels of GLAST (Fig. $4 E, N$ and $N S$ ). Further isolation by centrifuging against a $30 \%$ sucrose solution yielded an actin-free fraction ( $\mathrm{N}$, purified nuclei as pellet in sucrose solution) and a supernatant (NS) containing actin.

\section{Glioma cells release glutamate in the presence of L-cystine}

As already demonstrated in Figure $1, \mathrm{Na}^{+}$-independent glutamate uptake in glioma cells can be almost completely inhibited by low concentrations of L-cystine, suggesting that $\mathrm{Na}^{+}$-independent glutamate uptake is mediated by cystine-glutamate exchange (Bannai and Kitamura, 1980). It is likely that in the absence of extracellular L-cystine, intracellular L-cystine can be used to exchange ${ }^{3} \mathrm{H}$-glutamate from the media, whereas the presence of extracellular L-cystine primarily reduces the L-cystine transmembrane gradient and inhibits glutamate uptake. In addition, presence of extracellular L-cystine likely reverses the exchanger, resulting in L-cystine uptake into the cell and glutamate release down its concentration gradient and into the extracellular space. To study the possible contribution of this exchanger to glutamate transport in glioma cells, we further examined the effects of L-cystine on glutamate transport.

To this end, we first examined glutamate release from glioma cells incubated in EBSS. In the absence of L-cystine, glutamate release in EBSS was marginal $(\sim 41-47 \mathrm{nmol} / \mathrm{mg}$, or $\sim 2 \mu \mathrm{M})$. However, adding L-cystine to the EBSS potently and dosedependently stimulated glutamate release from glioma cells (Fig. $5 A$ ). At concentration of $100 \mu \mathrm{M}$, L-cystine increased glutamate release 14 -fold over the L-cystine-free conditions at $5 \mathrm{hr}$ and 38 -fold at $14 \mathrm{hr}$ (Fig. 5B). The [Glu] orise could have only resulted from glutamate released from intracellular stores and is limited by the amount of glutamate precursors in the EBSS. We therefore tested the effects of exogenous glutamine on glutamate release. As the most important glutamate precursor, glutamine potentiated $[\mathrm{Glu}]_{\mathrm{o}}$ levels in STTG-1 cultures from 1.9-2.6 $\mu \mathrm{M}$ to 8.6-9.9 $\mu \mathrm{M}$ (after $3 \mathrm{hr}$ incubation). This increase was much lower than that induced by L-cystine alone, which increased [Glu] o over 31 $\mu \mathrm{M}$ after a $3 \mathrm{hr}$ incubation. However, if both glutamine and L-cystine were added together, they showed a synergistic effect and $[\mathrm{Glu}]_{\mathrm{o}}$ increased to levels above $100 \mu \mathrm{M}$ (Fig. 5B). In agree- 


\section{GLAST in cultured cells}
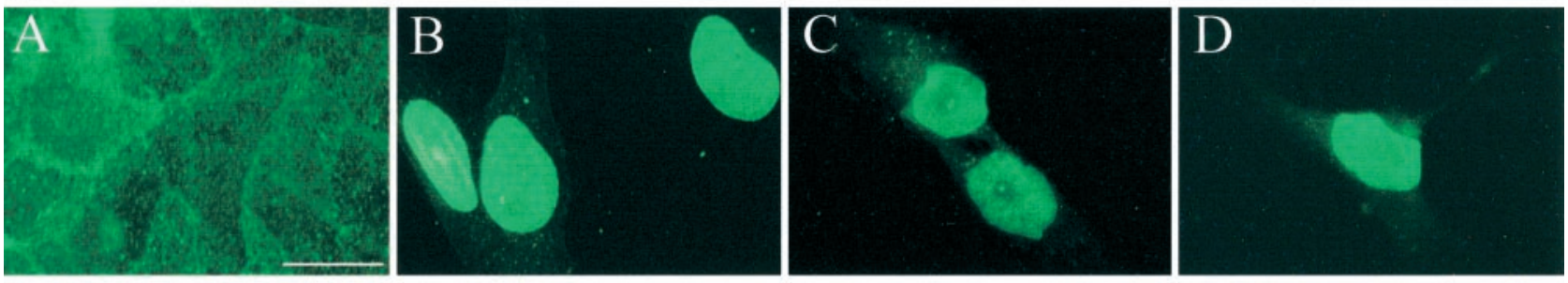

\section{GLAST in human biopsy tissues}
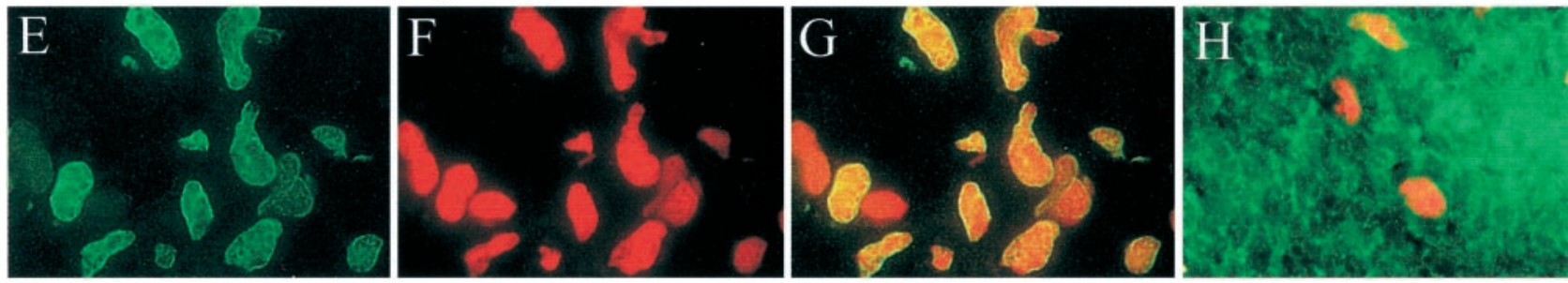

\section{GLT-1 in human biopsy tissues}
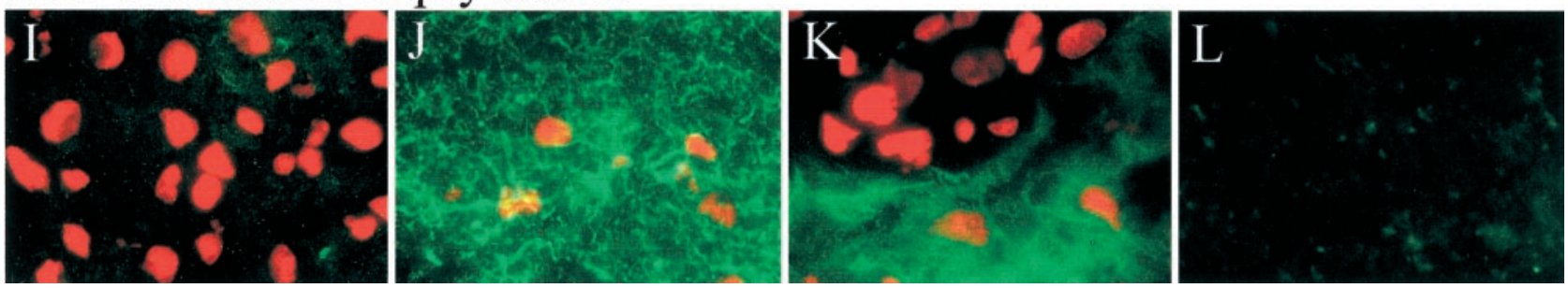

Figure 3. Immunohistochemical localization of glutamate transporters in cultured cells and human brain tissues. $A$, GLAST staining of cultured rat hippocampal astrocytes shows abundant staining in all aspects of the cell with more intense labeling at cell-cell junctions. $B-D$, Representative examples of GLAST expression in STTG-1 $(B)$, D54-MG $(C)$, and D65-MG $(D)$ cells show intensive GLAST staining in the cell nuclei with little staining on cell processes. $E-L$, Immunohistochemical staining of biopsy sections. $E-G$ show a representative GBM section stained for GLAST ( $E$ ), propidium iodide $(F)$, and superimposition of these to show colocalization in cell nuclei $(G)$. $H$ shows double staining of GLAST and propidium iodide in uninvolved brain tissue from the same patient (note that the density of nuclei is much lower than in GBM tissues). I, $K$, GBM tumor tissues double-stained for GLT-1 and propidium iodide. Areas with high nuclear densities exhibited no GLT-1 immunoreactivity, whereas comparison tissue from the same patient shows strong immunoreactivity for GLT-1 $(J)$. Occasionally, tumor tissue showed areas that appeared to be tumor margins in which the area with low density of nuclei stained prominently for GLT-1 (presumably normal brain), but areas with high densities of nuclei (presumably tumor) lack GLT-1 staining ( $K$ ). $L$, Secondary antibody and reagent control. Section adjacent to $(J)$ stained with FITC-conjugated goat anti-rabbit only. Scale bar: $A-L, 20 \mu \mathrm{m}$.

ment with the notion that glutamate is released from intracellular stores, the intracellular glutamate content $\left([\mathrm{Glu}]_{\mathrm{i}}\right)$ of glioma cells in EBSS gradually declined over a period of several hours. Notably, in the presence of L-cystine and absence of glutamine, the amount of glutamate released was more than twofold greater than the total loss of intracellular glutamate (data not shown), suggesting that glioma cells use intracellular glutamate precursors to generate glutamate.

To further substantiate the notion that the $\mathrm{Na}^{+}$-independent glutamate transport was caused by cystine-glutamate exchange, we performed tracer studies with ${ }^{35} \mathrm{~S}$-L-cystine. As expected, the rise of $[\mathrm{Glu}]_{\mathrm{o}}$ was accompanied by intracellular accumulation of ${ }^{35} \mathrm{~S}$-L-cystine. However, the ${ }^{35} \mathrm{~S}$ radioactivity quickly reached a plateau (Fig. 5C). Bannai and Ishii (1982) observed a similar phenomenon in fibroblast in which L-cystine was quickly converted to L-cysteine and most cysteine was released into the culture media. Subsequently, the L-cysteine in the media can be oxidized to cystine that can again become a substrate for cystine-glutamate exchange (Bannai and Ishii, 1988). This cystine-cysteine cycle may play an important role in neuron-glial interaction, because neurons can only use cysteine. The presence of astrocytes to convert media cystine to cysteine is important for maintaining neuronal glutathione levels (Sagara et al., 1993). In glioma cells, we also observed a rather rapid drop of ${ }^{35} \mathrm{~S}$ radioactivity if the cells were switched to unlabeled L-cystine (Fig. 5C). Furthermore, as is typical of this exchanger, L-cystine could be transported in both the presence and absence of $\mathrm{Na}^{+}$(Fig. 5D).

For a heteroexchange system of two substrates, A and B, which is only driven by the concentration gradient, driving forces for uptake of substrate $\mathrm{A}$ into cells is proportional to the ratio of $\left([\mathrm{A}]_{\mathrm{o}}\right)^{\mathrm{m}}\left([\mathrm{B}]_{\mathrm{i}}\right)^{\mathrm{n}} /\left([\mathrm{A}]_{\mathrm{i}}\right)^{\mathrm{m}}\left([\mathrm{B}]_{\mathrm{o}}\right)^{\mathrm{n}}$, where $\mathrm{m}$ and $\mathrm{n}$ stand for the number of $\mathrm{A}$ and $\mathrm{B}$ molecules transported per cycle, respectively. Reported tracer studies suggested that $\mathrm{m}=\mathrm{n}=1$ for cystineglutamate exchange (Kessler et al., 1987; Zaczek et al., 1987; Sato et al., 1999). Thus, increasing extracellular glutamate and cystine levels should mutually inhibit uptake of cystine or glutamate, respectively. This is indeed what we observed. Namely, extracellular glutamate competitively inhibited L-cystine uptake with an apparent $K_{\mathrm{i}}$ of $330 \mu \mathrm{M}$ (Fig. 6A,B). Similarly, extracellular L-cystine competitively inhibited $\mathrm{Na}^{+}$-independent glutamate uptake with an apparent $K_{\mathrm{i}}$ of $14 \mu \mathrm{M}$ (Fig. $6 C, D$ ). Interestingly, the $K_{\mathrm{m}}$ values of glutamate and cystine uptake are $32.3 \mu \mathrm{M}(41.2 \pm 3.3$ from three experiments) and $40.2 \mu \mathrm{M}(46.2 \pm 9.0$ from three experiments), respectively. In the literature, $K_{\mathrm{m}}$ of L-cystine and 

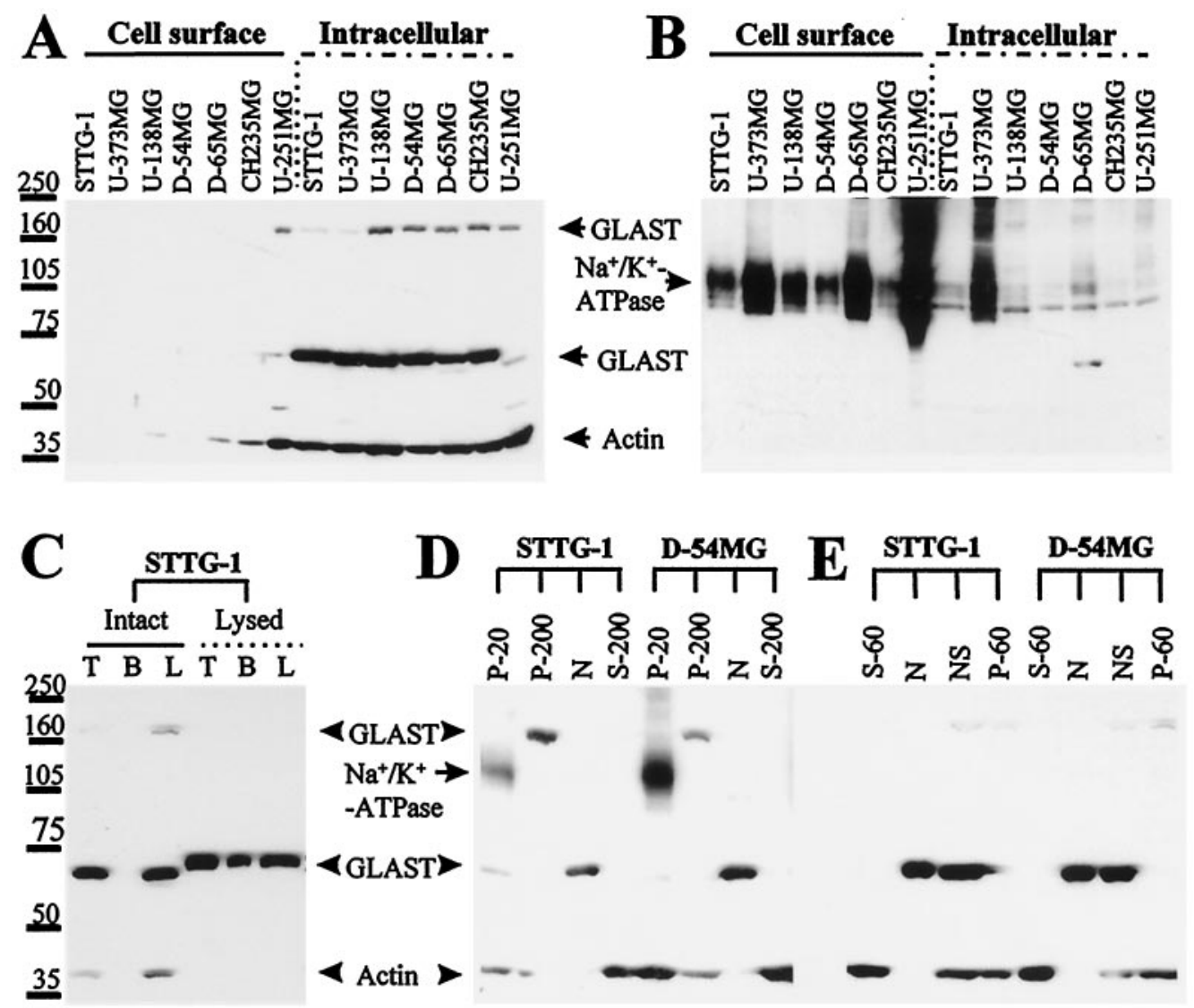

Figure 4. Localization of GLAST in human glioma cell lines. $A$, Cell surface proteins were separated from intracellular proteins through biotinylation, followed by separation with a biotin-avidin interaction. No cell surface expression of GLAST was detected in these cells, whereas GLAST remained at the intracellular fraction. $B$, Blot of $A$ was stripped and reprobed for the cell surface protein $\mathrm{Na}^{+} / \mathrm{K}^{+}$-ATPase. It appeared that the majority of $\mathrm{Na}^{+} / \mathrm{K}^{+}$-ATPase was located in the biotinylated cell surface fraction. $C$, GLAST in osmotically lysed STTG-1 cells but not in intact ones was accessible for biotinylation. Biotinylation increases the apparent molecular weight by $\sim 5 \mathrm{kDa}$. $T$, Total lysate; $B$, biotinylated fraction; $L$, total lysate minus biotinylated proteins. $D$, Subcellular fractionation of glioma cells; the blot was probed with GLAST plus actin, subsequently stripped, and probed with $\mathrm{Na}^{+} / \mathrm{K}^{+}$-ATPase. Then, the two staining patterns were superimposed for comparison. GLAST monomers were found in the nuclear fraction $(N)$, and the multimers were found in the P-200 fraction. The P-20 fraction that contained the cell surface marker $\mathrm{Na}^{+} / \mathrm{K}^{+}-\mathrm{ATPase}$ had a small amount of GLAST, which was likely caused by the presence of endoplasmic reticulum in the P-20 fraction. E, Subcellular fractionation of glioma cells using digitonin. Only the N and NS part that were pelleted by centrifugation at $500 \times g$ contained significant amounts of GLAST. Fraction N and NS were further separated by centrifugation against a $30 \%$ sucrose solution. Pellet N contained purified nuclei, and the supernatant NS consisted of nuclei that were associated with actin and potentially some other membrane structures.

glutamate in fibroblast cell line is 43 and $200 \mu \mathrm{M}$, respectively (Bannai and Kitamura, 1980). Because the exchanger operates with an obligatory molar ratio of 1:1 (Sato et al., 1999), the exchange process involved both the extracellular substrate and the cytosol counter-transport substrate. In light of the similarity in the $K_{\mathrm{m}}$ for glutamate and L-cystine, the observed difference in $K_{\mathrm{i}}$ values for extracellular glutamate and L-cystine are most likely caused by differences in the driving force for each substrate, which is determined by both the intracellular and extracellular substrate concentrations. We determined [Glu $]_{\mathrm{i}}$ to be $\sim 10 \mathrm{~mm}$ in glioma cells that were incubated for $10 \mathrm{~min}$ in glutamine-free solution, whereas the intracellular L-cystine levels under the same conditions was much lower, namely $\sim 0.2 \mathrm{~mm}$. Consequently, it required larger changes in $[\mathrm{Glu}]_{\mathrm{o}}$ than in [L-cystine $]_{\mathrm{o}}$ to achieve the same level of alteration in the transmembrane ratio of [Glu] and [L-cystine], respectively. Thus, the $K_{\mathrm{i}}$ of glutamate appeared higher than the $K_{\mathrm{i}}$ of L-cystine. The above data further support the notion that $\mathrm{Na}^{+}$-independent glutamate transport, which accounts for a significant portion of all glutamate transport in glioma cells, is mediated by a cystine-glutamate exchange process.

\section{Phenylglycine derivatives block glutamate release from glioma cells by inhibiting cystine-glutamate exchange}

We described previously that, in cultured astrocytes several glutamate analogs, particularly those frequently used as metabotropic glutamate receptor (mGluR) agonists or antagonists, can reduce extracellular glutamate levels. However, their effects could not be blocked by mGluR antagonists or by altering their underlying signaling pathways, and their effects were likely caused by decreased release rather than enhanced uptake of glutamate (Ye and Sontheimer, 1999a). Among these glutamate analogs, $S$-4CPG was the most effective in reducing $[\mathrm{Glu}]_{\mathrm{o}}$. We thus studied the effects of $S$-4CPG on glutamate release from glioma cells. When $S$-4CPG was applied simultaneously with glutamatedepleted culture medium, $S$-4CPG led to a marked and dosedependent decrease in glutamate release (Fig. $7 A$ ). Its stereoisomer $R$-4CPG was 1000 -fold less effective (data not shown). 

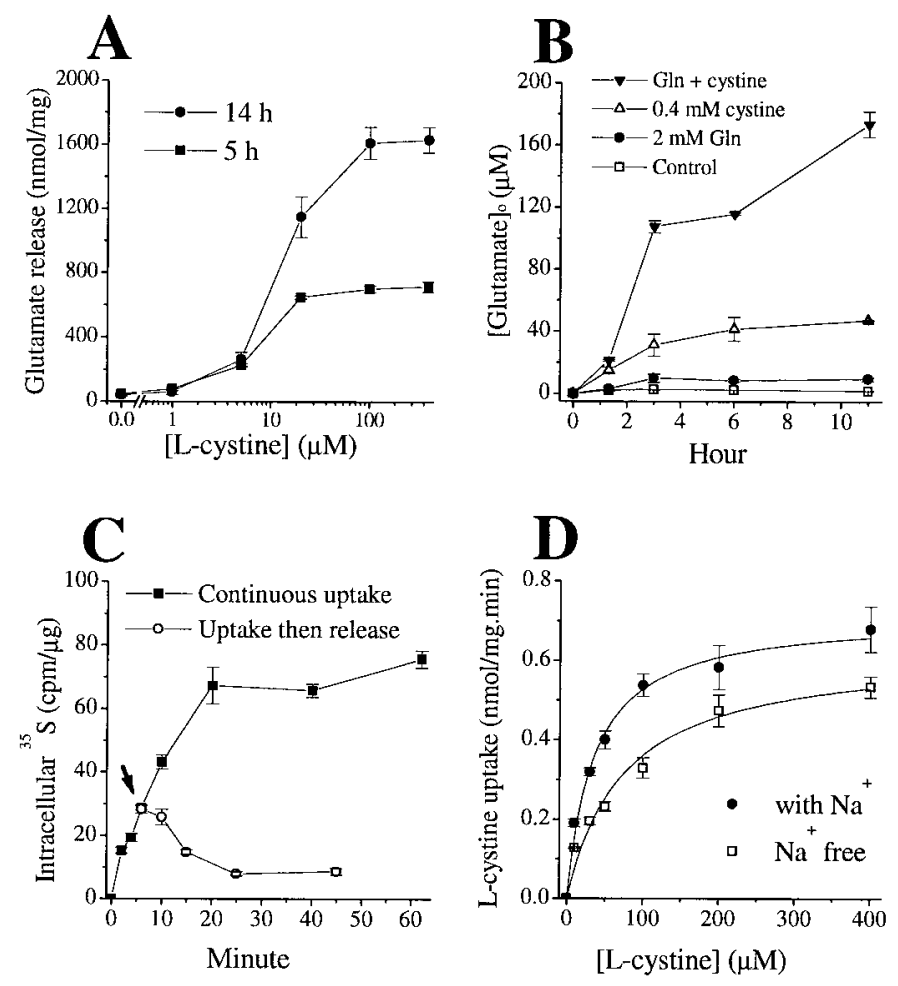

Figure 5. Cystine-glutamate exchange mediates glutamate release and cystine uptake in human glioma cells (STTG-1 cells). A, L-Cystine stimulated glutamate release in a dose- and time-dependent manner, $\mathrm{EC}_{50}$ of $\sim 15 \mu \mathrm{M}$. B, L-Cystine ( $0.4 \mathrm{mM})$ gradually increased extracellular glutamate concentrations, and this effect was enhanced by the presence of glutamine $(2.0 \mathrm{mM}) . C$, Intracellular ${ }^{35} \mathrm{~S}$ reading reached a plateau in the continuous presence of $1 \mu \mathrm{Ci} / \mathrm{ml}{ }^{35} \mathrm{~S}$-L-cystine and $100 \mu \mathrm{M}$ unlabeled L-cystine. After 6 min incubation, some cells were switched to $100 \mu \mathrm{M}$ unlabeled L-cystine alone (arrow), and the intracellular ${ }^{35} \mathrm{~S}$ reading gradually declined. $D$, L-Cystine uptake did not depend on the presence of $\mathrm{Na}^{+}$. Data are means \pm SE; $n=4-6$.
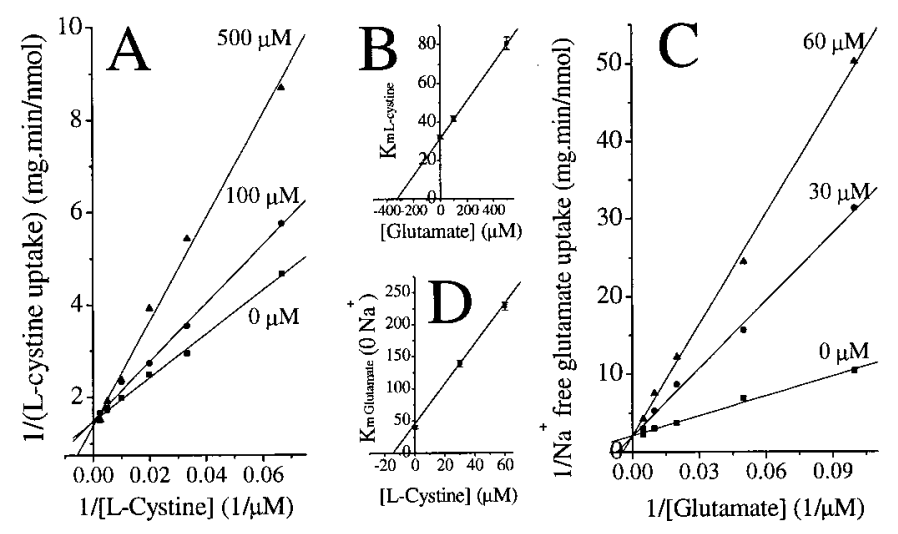

Figure 6. Mutual competitive inhibition of glutamate and L-cystine uptake in STTG-1 glioma cells. $A$, Lineweaver-Burk plot of L-cystine uptake in the presence of glutamate. $B$, Glutamate competitively inhibited L-cystine uptake with a $\mathrm{K}_{\mathrm{i}}$ of $\sim 330 \mu \mathrm{M}$. $C, D$, L-Cystine competitively inhibited $\mathrm{Na}^{+}$-independent glutamate transport with a $\mathrm{K}_{\mathrm{i}}$ of $\sim 15 \mu \mathrm{M}$. Data are means \pm SE; $n=4$.

Because we demonstrated above that L-cystine was required to stimulate a maximal release of glutamate from glioma cells, we also evaluated the effects of cystine-induced glutamate release in the presence of $100 \mu \mathrm{M} S$-4CPG. Coapplication of $S$-4CPG dra-
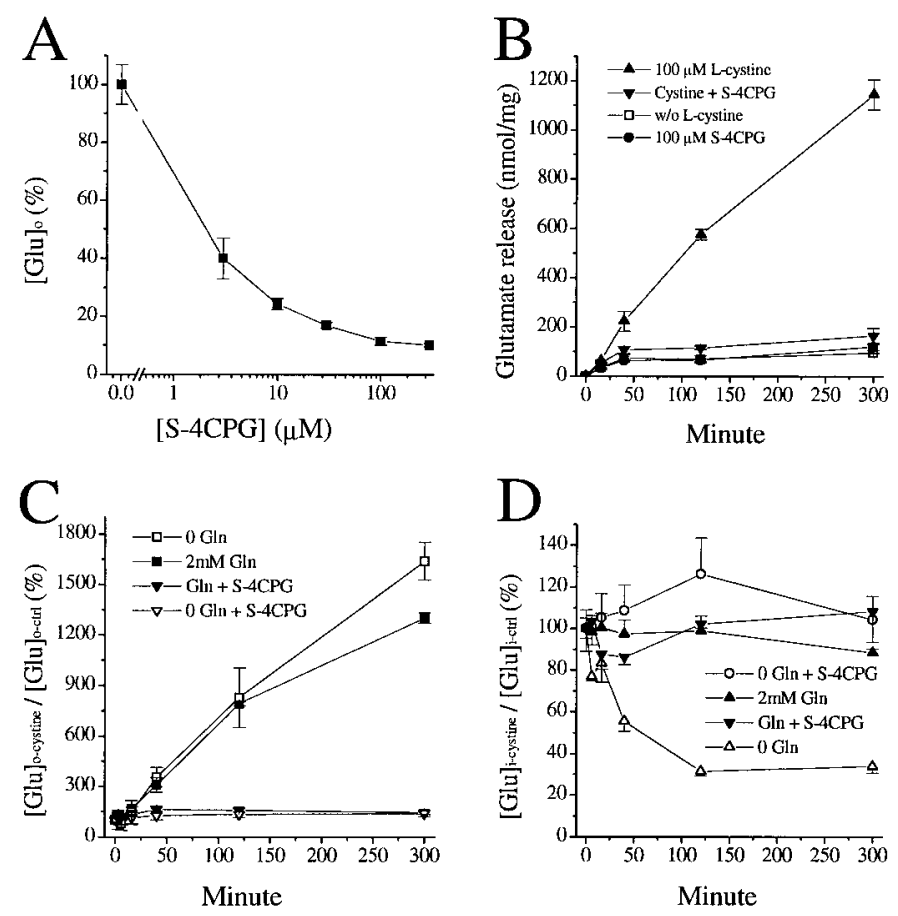

Figure 7. Inhibition of cystine-induced glutamate release by $S$-4CPG. $A$, Dose-dependent reduction of extracellular glutamate levels ([Glu $\left.]_{\mathrm{o}}\right)$ sampled $5 \mathrm{hr}$ after incubating glioma cells in glutamate-depleted culture media, in the presence of various concentration of $S$-4CPG. $B, S-4 \mathrm{CPG}$ specifically inhibited cystine-induced $[\mathrm{Glu}]_{\mathrm{o}}$ elevation but was without effect in the absence of L-cystine. $C, S$-4CPG exerted a similar degree of inhibition on L-cystine-induced glutamate release, regardless of the presence of extracellular glutamine. $D, S$-4CPG inhibited the cystine-induced decline of intracellular glutamate content $\left([\mathrm{Glu}]_{\mathrm{i}}\right)$, as did $2 \mathrm{~mm}$ glutamine. Data are means $\pm \mathrm{SE} ; n=4$.

matically reduced the L-cystine-elicited $[\mathrm{Glu}]_{\mathrm{o}}$ release. However, in the absence of L-cystine, $S$-4CPG did not reduce the [Glu] levels (Fig. $7 B$ ), suggesting that $S$-4CPG works specifically on the cystine-glutamate exchanger. As shown above, glutamine increases the total amount of glutamate released in both the presence and absence of L-cystine (Fig. $5 B$ ). However, the degree of increase in $[\mathrm{Glu}]_{\mathrm{o}}$ by L-cystine was essentially identical, irrespective of the presence of glutamine. Furthermore, $S$-4CPG exerted similar levels of inhibition on L-cystine-induced [Glu] elevation (Fig. 7C), regardless of the presence of glutamine. Combined with the fact that glutamine increased the total amount of glutamate release, this suggests that the presence of glutamine provides better glutamate source for cystine-glutamate exchange but does not directly interfere with the exchange processes. In line with the abolishment of cystine-stimulated [Glu] elevation by $S$-4CPG, $S$-4CPG also blocked the cystine-induced decline of $[\mathrm{Glu}]_{\mathrm{i}}$. However, in the presence of glutamine, which can be converted to glutamate and is sufficient to prevent cystineinduced decline of $[\mathrm{Glu}]_{\mathrm{i}}, S$-4CPG did not further alter $[\mathrm{Glu}]_{\mathrm{i}}$ (Fig. 7D). These data again suggest that glioma cells are sensitive to a drop in $[\mathrm{Glu}]_{\mathrm{i}}$ and are committed to generating glutamate from its precursors, regardless of the elevation of extracellular glutamate levels, which is contrary to normal astrocytes that appear to be dedicated to maintaining low $[\mathrm{Glu}]_{\mathrm{o}}$.

The above results suggest that $S-4 C P G$ specifically blocks L-cystine-induced glutamate release, which is mediated by Lcystine-glutamate exchange. Several other carboxyphenylglycine 


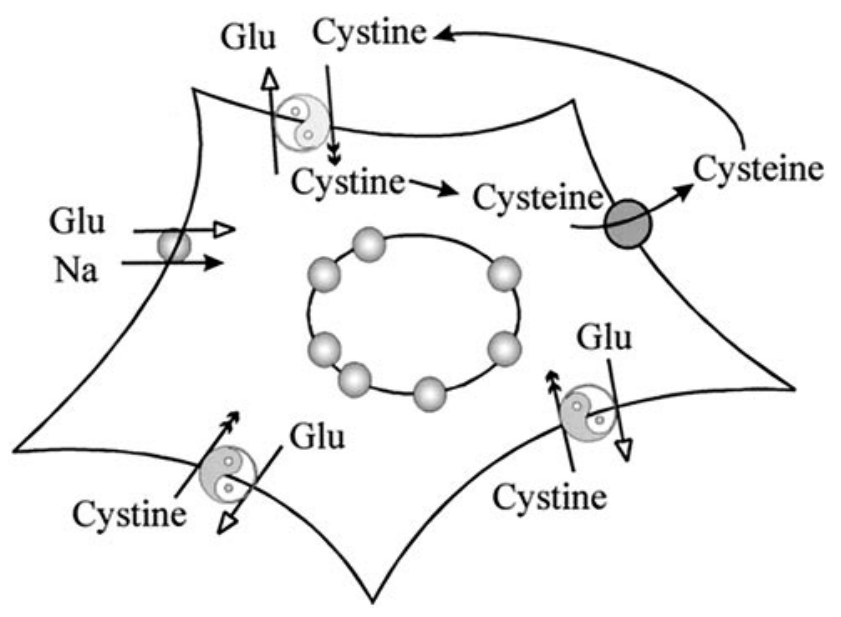

Figure 8. Glutamate handling by glioma cells. Reduction-mislocalization of $\mathrm{Na}^{+}$-dependent glutamate transporters makes glioma cells incapable of sufficiently removing glutamate from the extracellular space; cystine-glutamate exchangers mediate glutamate efflux and cystine uptake in the presence of extracellular L-cystine. The transported cystine can be reduced to cysteine and released to the extracellular space, where cysteine is likely to be oxidized to cystine and again serves as substrate for cystine-glutamate exchange.

derivatives, including $S$-4C3H-PG and $S$-3C4H-PG, also exerted inhibition on cystine-glutamate exchange (data not shown). In addition, $S$-4CPG did not inhibit $\mathrm{Na}^{+}$-dependent glutamate-Daspartate uptake in astrocytes.

\section{DISCUSSION}

Although astrocytes use $\mathrm{Na}^{+}$-dependent glutamate transport to actively control extracellular glutamate $[\mathrm{Glu}]_{\mathrm{o}}$, their malignant glioma counterparts are deficient in this function. Indeed, glioma cells release glutamate into the extracellular space rather than remove it. Our data suggest that two functional changes account for this difference. First, of the two abundant glial $\mathrm{Na}^{+}$dependent transporters GLT-1 and GLAST, only GLAST is expressed in glioma cells at levels comparable with that of normal astrocytes. However, the GLAST protein appears to accumulate in the nuclear membrane with little cell surface expression. These findings are consistent with the up to 100 -fold reduction in $\mathrm{Na}^{+}$dependent glutamate uptake observed in glioma cells. Second, glioma cells display strong $\mathrm{Na}^{+}$-independent cystine-glutamate exchange activity. Because $[\mathrm{Glu}]_{\mathrm{i}}$ is much higher than $[\mathrm{Glu}]_{\mathrm{o}}$, the glutamate gradient greatly outweighs the transmembrane L-cystine gradient. This is important particularly with regard to the presence of L-cystine in the culture media in which cystine uptake in tandem with glutamate efflux is likely to be the dominant direction of this exchange system. Furthermore, downhill movement of glutamate at $[\mathrm{Glu}]_{\mathrm{i}} \sim 10 \mathrm{~mm}$ and the presence of extracellular L-cystine at $\sim 100-200 \mu \mathrm{M}$ enables this exchanger to operate at close to maximal rates. In this case, cystine-glutamate exchange-induced glutamate efflux outweighs the weak $\mathrm{Na}^{+}$dependent inward glutamate transport leading to the accumulation of glutamate in the extracellular space. This process is illustrated in a schematic drawing in Figure 8. Under normal condition, e.g., in cells that also express sufficient $\mathrm{Na}^{+}$-dependent glutamate uptake, the activity of cystine-glutamate exchange would not pose a problem because glutamate released by this exchanger would again become the substrate for $\mathrm{Na}^{+}$-dependent glutamate uptake. However, this glutamate release may signifi- cantly contribute to the discrepancy between measured $[\mathrm{Glu}]_{\mathrm{o}}$, both in vitro and in vivo, and the theoretic minimal maintainable [Glu $]_{o}$ predicted by the stoichiometry of $\mathrm{Na}^{+}$-dependent glutamate transport (Attwell et al., 1993; Zerangue and Kavanaugh, 1996a).

Under conditions in which $\mathrm{Na}^{+}$-dependent glutamate transporters are not functioning sufficiently, as is the case in glioma cells, it is possible that the cystine-glutamate exchange will contribute to neurotoxic levels of glutamate released by gliomas. In typical culture conditions, L-cystine is present in concentrations of $\sim 100-200 \mu \mathrm{M}$, which is sufficient to drive glutamate release from gliomas to reach neurotoxic concentrations. This is indeed what we observed in studies in which hippocampal neurons were cocultured with glioma cells. This led to widespread neurotoxicity, which could be completely prevented by the NMDA receptor antagonists MK-801 or $\mathrm{D}(-)$-2-amino-5-phosphonopentanoic acid (Ye and Sontheimer, 1999b). In addition, this toxicity could be inhibited by applying $S$-4CPG to the cocultures, consistent with $S$-4CPG inhibition of cystine-glutamate exchange. Interestingly, it has been shown that during hypoxia-ischemia, cysteine levels are markedly elevated (Slivka and Cohen, 1993; PukaSundvall et al., 1996). L-Cysteine can interfere and block $\mathrm{Na}^{+}$dependent glutamate transport (Zerangue and Kavanaugh, 1996b) and may thus exacerbate glutamate accumulation caused by energy depletion. Furthermore, L-cysteine can be readily oxidized to L-cystine, thus possibly leading to glutamate release through the cystine-glutamate exchange as described here for glioma cells.

Although astrocytes expressed both GLAST and GLT-1 in their plasma membrane, GLT-1 was primarily absent and GLAST appeared to be mislocalized to the nuclear membrane of glioma cells. We do not know what causes this nuclear localization of GLAST, nor can we be certain that the GLAST protein detected in the nuclear membrane by antibodies corresponds to functional transporters. Altering cell surface expression levels has been shown to be an effective way to control transporter activity in C6 glioma cells and HEK293 cells (Qian et al., 1997; Davis et al., 1998). In normal astrocytes, the majority of transporter protein (GLAST and GLT-1) is located in the plasma membrane (Chaudhry et al., 1995). To our knowledge, it has not been shown that glutamate transporters can be localized in cell nuclei. A mislocalization of GLAST not only occurred in cultured glioma cell lines but was also observed in most acute glioblastome biopsies. Importantly, however, uninvolved brain tissue from the same patients did showed normal membraneassociated GLAST staining with little evidence of nuclear localization. These data suggest that the mislocalization of GLAST is an intrinsic feature of glioma cells and not an artifact from prolonged cell culture. It is worth pointing out that there are some cells in the GBM tissue sections that are not labeled with GLAST (Fig. 3G), which are likely some nontumor cells within the tumor. In addition, results from subcellular fractionation (Fig. $4 D$ ) suggest different distribution patterns of GLAST monomers and multimers in glioma cells, and the multimers appear to be resistant to $\beta$-mercaptoethanol. Because the P-200 fraction likely consists of Golgi and other low-density vesicles, the role of the differential localization of monomers and multimers remains to be elucidated, as are the cellular events that lead to these phenomena.

Reduction of GLT-1 was also observed in human GBM biopsy tissue, and this is particularly evident in the border between tumor and normal tissue (Fig. $3 K$ ). Although all the tested cell 
lines displayed greatly reduced glutamate and D-aspartate uptake compared with normal astrocytes, variation exist among cell lines, especially with regard to D-aspartate uptake in which U-251MG and D-65MG cells exhibited higher D-aspartate transport rates than other cell lines. Interestingly, in STTG-1 and D-65MG cells, D-aspartate $(50 \mu \mathrm{M})$ uptake was reduced 57.6$68.0 \%$ by $5 \mathrm{~mm}$ dihydrokinate, and $\mathrm{Na}^{+}$-dependent glutamate $(50$ $\mu \mathrm{M})$ uptake was reduced by $34.9-47.2 \%$. However, $5 \mathrm{~mm}$ D, Lthreo-hydroxyaspartate nearly completely blocked this residual $\mathrm{Na}^{+}$-dependent D-aspartate-glutamate uptake. We do not know whether the residual levels of GLT-1 shown in Figure 2 are functional transporters and could account for these dihydrokainate-sensitive uptake.

It is worth emphasizing that, even without any exogenous supply of glutamate precursor molecules, such as glutamine, glioma cells can still release glutamate in amounts that exceeds their intracellular content. Glioma cells can actively synthesize glutamate from precursor stores to compensate for the release. In the presence of exogenous glutamine, glutamate release was enhanced and the decline of $[\mathrm{Glu}]_{\mathrm{i}}$ was completely blocked, suggesting that deamination is a key pathway for the production of glutamate by glioma cells in the presence of glutamine. Interestingly, the hyperpermeable blood vessels in tumor tissues can provide tumor cells with better access to various nutrition factors, including glutamine in the blood than normal brain tissue. In the presence of L-cystine, these glioma cells could thus serve as a constant glutamate source.

It is difficult to extrapolate from our in vitro data to the in vivo significance of these findings. The extracellular space in vivo is usually $<20 \%$ of the total volume, whereas in an in vitro system extracellular space is $\sim 10^{3}$-fold larger than the cell volume. Small amounts of glutamate can effectively raise the $[\mathrm{Glu}]_{\mathrm{o}}$ to toxic levels. For instance, a $2 \mathrm{nmol} \cdot \mathrm{mg}^{-1} \cdot \mathrm{min}^{-1}$ glutamate release can increase $[\mathrm{Glu}]_{\mathrm{o}}$ in a volume of $2 \mu \mathrm{l}$ (cells of $1 \mathrm{mg}$ of protein take $\sim 10 \mu \mathrm{l}$ of space) at a rate of $1 \mathrm{~mm} / \mathrm{min}$; thus, our in vitro data may underestimate the true extent of the glutamate release by glioma cells in vivo. On the other hand, release of glutamate by glioma cells requires the presence of extracellular L-cystine. The concentrations of L-cystine in and around gliomas in vivo are unknown. In normal brain, cystine concentration in the CSF are at submicromolar levels (Murphy et al., 1989), but the trafficking of cystine-cysteine between neurons and glia may likely make the cystine concentration in the extracellular space much higher than that in CSF and could possibly reach micromolar levels. Furthermore, the compromised blood-brain barrier may also allow brain tumor cells access to blood cystine, which is $\sim 100 \mu \mathrm{M}$. As determined in our experiments, the $K_{\mathrm{m}}$ for cystine-induced glutamate release from STTG-1 glioma cell is $\sim 15 \mu \mathrm{M}$. Thus, micromolar levels of cystine surrounding tumor cells can induce substantial glutamate release. Importantly, because L-cystine tends to be reduced to cysteine and released by cells, the released cysteine can readily be oxidized to cystine and again become a substrate for cystine-glutamate exchange. This cystine-cysteine shuttle could provide a continuous substrate for cystine-glutamate exchanger and hence continuously induce the release of glutamate from glioma cells.

Although the biological implications of glutamate release and the ensuing neurotoxicity are evident, the role, if any, that this process may have for gliomas is unclear. We could only speculate that glutamate release might allow these aggressively growing tumors to actively kill surrounding neurons, thereby creating space to expand. These results also suggest that seizures often observed in patients with glioma might be caused by glutamate spillage from the tumor into the peritumoral neuronal tissue. In addition, the neuronally released glutamate after synaptic transmission may accumulate by lack of sufficient glutamate uptake into the nearby glioma cells.

\section{REFERENCES}

Arriza JL, Eliasof S, Kavanaugh MP, Amara SG (1997) Excitatory amino acid transporter 5, a retinal glutamate transporter coupled to a chloride conductance. Proc Natl Acad Sci USA 94:4155-4160.

Attwell D, Barbour B, Szatkowski M (1993) Nonvesicular release of neurotransmitter. Neuron 11:401-407.

Bannai S, Ishii T (1982) Transport of cystine and cysteine and cell growth in cultured human diploid fibroblasts: effect of glutamate and homocysteate. J Cell Physiol 112:265-272.

Bannai S, Ishii T (1988) A novel function of glutamine in cell culture: utilization of glutamine for the uptake of cystine in human fibroblasts. J Cell Physiol 137:360-366.

Bannai S, Kitamura E (1980) Transport interaction of L-cystine and L-glutamate in human diploid fibroblasts in culture. J Biol Chem 255:2372-2376.

Bergles DE, Jahr CE (1998) Glial contribution to glutamate uptake at Schaffer collateral-commissural synapses in the hippocampus. J Neurosci 18:7709-7716.

Bronfman M, Loyola G, Koenig CS (1998) Isolation of intact organelles by differential centrifugation of digitonin-treated hepatocytes using a table Eppendorf centrifuge. Anal Biochem 255:252-256.

Chaudhry FA, Lehre KP, van Lookeren Campagne M, Ottersen OP, Danbolt NC, Storm-Mathisen J (1995) Glutamate transporters in glial plasma membranes: highly differentiated localizations revealed by quantitative ultrastructural immunocytochemistry. Neuron 15:711-720.

Cho Y, Bannai S (1990) Uptake of glutamate and cysteine in C6 glioma cells and in cultured astrocytes. J Neurochem 55:2091-2097.

Choi DW (1988) Glutamate neurotoxicity and diseases of the nervous system. Neuron 1:623-634.

Davis KE, Straff DJ, Weinstein EA, Bannerman PG, Correale DM, Rothstein JD, Robinson MB (1998) Multiple signaling pathways regulate cell surface expression and activity of the excitatory amino acid carrier 1 subtype of Glu transporter in C6 glioma. J Neurosci 18:2475-2485.

Fairman WA, Vandenberg RJ, Arriza JL, Kavanaugh MP, Amara SG (1995) An excitatory amino-acid transporter with properties of a ligand-gated chloride channel. Nature 375:599-603.

Fosse VM, Kolstad J, Fonnum F (1986) A bioluminescence method for the measurement of L-glutamate: applications to the study of changes in the release of 1-glutamate from lateral geniculate nucleus and superior colliculus after visual cortex ablation in rats. J Neurochem 47:340-349.

Haugeto O, Ullensvang K, Levy LM, Chaudhry FA, Honore T, Nielsen M, Lehre KP, Danbolt NC (1996) Brain glutamate transporter proteins form homomultimers. J Biol Chem 271:27715-27722.

Hertz L, Murthy CRK, Schousboe A (1988) Metabolism of glutamate and related amino acids. In: The biochemical pathology of astrocytes (Norenberg MD, Hertz L, Schousboe A, eds), pp 395-406. New York: Liss.

Kanai Y, Hediger MA (1992) Primary structure and functional characterization of a high-affinity glutamate transporter. Nature 360:467-471.

Kessler M, Baudry M, Lynch G (1987) Use of cystine to distinguish glutamate binding from glutamate sequestration. Neurosci Lett 81:221-226.

Kimelberg HK, Mongin AA (1998) Swelling-activated release of excitatory amino acids in the brain: Relevance for pathophysiology. Contrib Nephrol 123:240-257.

Kimelberg HK, Pang S, Treble DH (1989) Excitatory amino acidstimulated uptake of ${ }^{22} \mathrm{Na}^{+}$in primary astrocyte cultures. J Neurosci 9:1141-1149.

Laake JH, Slyngstad TA, Haug F-MS, Ottersen OP (1995) Glutamine from glial cells is essential for the maintenance of the nerve terminal pool of glutamate: Immunogold evidence from hippocampal slice cultures. J Neurochem 65:871-881.

Lehre KP, Danbolt NC (1998) The number of glutamate transporter subtype molecules at glutamatergic synapses: chemical and stereological quantification in young adult rat brain. J Neurosci 18:8751-8757.

Lehre KP, Levy LM, Ottersen OP, Storm-Mathisen J, Danbolt NC (1995) Differential expression of two glial glutamate transporters in the 
rat brain: quantitative and immunocytochemical observations. J Neurosci 15:1835-1853.

Levi G, Patrizio M (1992) Astrocyte heterogeneity: endogenous amino acid levels and release evoked by non- $N$-methyl-D-aspartate receptor agonists and by potassium-induced swelling in type- 1 and type- 2 astrocytes. J Neurochem 58:1943-1952.

Lipton SA, Rosenberg PA (1994) Excitatory amino acids as a final common pathway for neurologic disorders. N Engl J Med 330:613-622.

Longuemare MC, Swanson RA (1995) Excitatory amino acid release from astrocytes during energy failure by reversal of sodium-dependent uptake. J Neurosci Res 40:379-386.

Magistretti PJ, Pellerin L, Rothman DL, Shulman RG (1999) Energy on demand. Science 283:496-497.

Murphy TH, Miyamoto M, Sastre A, Schnaar RL, Coyle JT (1989) Glutamate toxicity in a neuronal cell line involves inhibition of cystine transport leading to oxidative stress. Neuron 2:1547-1558.

Murphy TH, Schnaar RL, Coyle JT (1990) Immature cortical neurons are uniquely sensitive to glutamate toxicity by inhibition of cystine uptake. FASEB J 4:1624-1633.

Nicholls D, Attwell D (1990) The release and uptake of excitatory amino acids. Trends Pharmacol Sci 11:462-468.

Olney JW (1982) The toxic effects of glutamate and related compounds in the retina and the brain. Retina 2:341-359.

Paillas JE (1994) A review of 2,413 tumors operated over a 30-year period. J Neuroradiol 2:79-106.

Peghini P, Janzen J, Stoffel W (1997) Glutamate transporter EAAC-1deficient mice develop dicarboxylic aminoaciduria and behavioral abnormalities but no neurodegeneration. EMBO J 16:3822-3832.

Piani D, Fontana A (1994) Involvement of the cystine transport system $\mathrm{x}_{\mathrm{c}}{ }^{-}$in the macrophage-induced glutamate-dependent cytotoxicity to neurons. J Immunol 152:3578-3585.

Pines G, Danbolt NC, Bjoras M, Zhang Y, Bendahan A, Eide L, Koepsell H, Storm-Mathisen J, Seeberg E, Kanner BI (1992) Cloning and expression of a rat brain L-glutamate transporter. Nature 360:464-467.

Puka-Sundvall M, Gilland E, Bona E, Lehmann A, Sandberg M, Hagberg H (1996) Development of brain damage after neonatal hypoxia-ischemia: excitatory amino acids and cysteine. Metab Brain Dis 11:109-123.

Qian Y, Galli A, Ramamoorthy S, Risso S, DeFelice LJ, Blakely RD (1997) Protein kinase C activation regulates human serotonin transporters in HEK-293 cells via altered cell surface expression. J Neurosci $17: 45-57$.

Rothstein JD, Tabakoff B (1984) Alteration of striatal glutamate release after glutamine synthetase inhibition. J Neurochem 43:1438-1446.

Rothstein JD, Tsai G, Kuncl RW, Clawson L, Cornblath DR, Drachman DB, Pestronk A, Stauch BL, Coyle JT (1990) Abnormal excitatory amino acid metabolism in amyotrophic lateral sclerosis. Ann Neurol $28: 18-25$

Rothstein JD, Martin L, Levey AI, Dykes-Hoberg M, Jin L, Wu D, Nash N, Kuncl RW (1994) Localization of neuronal and glial glutamate transporters. Neuron 13:713-725.

Rothstein JD, Van Kammen M, Levey AI, Martin LJ, Kuncl RW (1995) Selective loss of glial glutamate transporter GLT-1 in amyotrophic lateral sclerosis. Ann Neurol 38:73-84.

Rothstein JD, Dykes-Hoberg M, Pardo CA, Bristol LA, Jin L, Kuncl RW, Kanai Y, Hediger MA, Wang YF, Schielke JP, Welty DF (1996) Knockout of glutamate transporters reveals a major role for astroglial transport in excitotoxicity and clearance of glutamate. Neuron 16:675-686.

Sagara J, Miura K, Bannai S (1993) Maintenance of neuronal glutathione by glial cells. J Neurochem 61:1672-1676.
Sato H, Kuriyama-Matsumura K, Siow RCM, Ishii T, Bannai S, Mann GE (1998) Induction of cystine transport via system $\mathrm{x}_{\mathrm{c}}{ }^{-}$and maintenance of intracellular glutathione levels in pancreatic acinar and islet cell lines. Biochim Biophys Acta 1414:85-94.

Sato H, Tamba M, Ishii T, Bannai S (1999) Cloning and expression of a plasma membrane cystine/glutamate exchange transporter composed of two distinct proteins. J Biol Chem 274:11455-11458.

Sibson NR, Dhankhar A, Mason GF, Behar KL, Rothman DL, Shulman $\mathrm{RG}$ (1997) In vivo ${ }^{13} \mathrm{C}$ NMR measurements of cerebral glutamine synthesis as evidence for glutamate-glutamine cycling. Proc Natl Acad Sci USA 94:2699-2704.

Slivka A, Cohen G (1993) Brain ischemia markedly elevates levels of the neurotoxic amino acid, cysteine. Brain Res 608:33-37.

Stachowiak MK, Moffett J, Joy A, Puchacz E, Florkiewicz R, Stachowiak EK (1994) Regulation of bFGF gene expression and subcellular distribution of bFGF protein in adrenal medullary cells. J Cell Biol 127:203-223.

Storck T, Schulte S, Hofmann K, Stoffel W (1992) Structure, expression, and functional analysis of a $\mathrm{Na}^{+}$-dependent glutamate/aspartate transporter from rat brain. Proc Natl Acad Sci USA 89:10955-10959.

Szatkowski M, Barbour B, Attwell D (1990) Non-vesicular release of glutamate from glial cells by reversed electrogenic glutamate uptake. Nature 348:443-446.

Tanaka K, Watase K, Manabe T, Yamada K, Watanabe M, Takahashi K, Iwama H, Nishikawa T, Ichihara N, Kikuchi T, Okuyama S, Kawashima N, Hori S, Takimoto M, Wada K (1997) Epilepsy and exacerbation of brain injury in mice lacking the glutamate transporter GLT-1. Science 276:1699-1702.

Torp R, Danbolt NC, Babaie E, Bjoras M, Seeberg E, Storm-Mathisen J, Ottersen OP (1994) Differential expression of two glial glutamate transporters in the rat brain: an in situ hybridization study. Eur J Neurosci 6:936-942.

Waniewski RA, Martin DL (1986) Exogenous glutamate is metabolized to glutamine and exported by rat primary astrocyte cultures. J Neurochem 47:304-313.

Watanabe H, Bannai S (1987) Induction of cystine transport activity in mouse peritoneal macrophages. J Exp Med 165:628-640.

Whittemore SR, Neary JT, Kleitman N, Sanon HR, Benigno A, Donahue RP, Norenberg MD (1994) Isolation and characterization of conditionally immortalized astrocyte cell lines derived from adult human spinal cord. Glia 10:211-226.

Ye ZC, Sontheimer H (1996) Cytokine modulation of glial glutamate uptake: a possible involvement of nitric oxide. NeuroReport 7:2181-2185.

Ye ZC, Sontheimer H (1998) Astrocytes protect neurons from neurotoxic injury by serum glutamate. Glia 22:237-248.

Ye ZC, Sontheimer H (1999a) Metabotropic glutamate receptor agonists reduce glutamate release from cultured astrocytes. Glia 25:270-281.

Ye ZC, Sontheimer H (1999b) Glioma cells release excitotoxic concentrations of glutamate. Cancer Res 59:4383-4391.

Zaczek R, Balm M, Arlis S, Drucker H, Coyle JT (1987) Quisqualatesensitive, chloride-dependent transport of glutamate into rat brain synaptosomes. J Neurosci Res 18:425-431.

Zerangue N, Kavanaugh MP (1996a) Flux coupling in a neuronal glutamate transporter. Nature 383:634-637.

Zerangue N, Kavanaugh MP (1996b) Interaction of L-cysteine with a human excitatory amino acid transporter. J Physiol (Lond) 493: 419-423. 